\title{
Using Research Review Articles to Answer Clinical Questions: A Guide to Finding and Evaluating Scholarly Work
}

\author{
Sandie Nadelson, RN, MSN, MSEd, PhD*, Louis Nadelson, PhD
}

School of Nursing and College of Education, University of Central Arkansas, 201 Donaghey Ave, Conway Arkansas, 72035, United States.

Article Details
Article Type: Mini Review
Received date: $29^{\text {th }}$ December, 2020
Accepted date: $31^{\text {th }}$ January, 2021
Published date: $03^{\text {rd }}$ February, 2021
"Corresponding Author: Sandie Nadelson, RN, MSN, MSEd, PhD, School of Nursing, College of Education, University of
Central Arkansas, 201 Donaghey Ave, Conway Arkansas, 72035, United States.. E-mail: Snadelson1@uca.edu
Citation: Nadelson, S. and Nadelson, L. (2021). Using Research Review Articles to Answer Clinical Questions: A Guide to
Finding and Evaluating Scholarly Work. J Comp Nurs Res Care 5(2):167. doi: https://doi.org/10.33790/jenrc11001688.
Copyright: $\odot 2021$, This is an open-access article distributed under the terms of the Creative Commons Attribution License
4.0, which permits unrestricted use, distribution, and reproduction in any medium, provided the original author and source are
credited.

\section{Abstract}

The purpose of our study is to provide health care professionals with practical approaches for finding and evaluating research review literature to guide evidence-based practice. With change continuously occurring in healthcare, questions arise daily regarding the evidence for clinical practice. Finding relevant and robust research that includes evidence of effective care options is essential to providing quality care. Unfortunately, locating useful research reports to guide practice among the vast number of scholarly publications can be overwhelming. Articles that evaluated multiple studies can save practitioners time and help answer care questions because they combine results from numerous studies within one article. What can be perplexing is that not all research review articles have the same purpose and analysis processes.In this article, we describe the main types of research review articles, explain which are most likely to provide direction for clinical practice andshare some useful tools for evaluating the worth of the different forms of scholarly writings. Finally, we include strategies for locating cost-free reviews of research articles so that you can get the articles needed to support your evidence-based practice.

Keywords: Systematic Review, Meta-analysis, Meta-Synthesis, Scoping Review, Evidence Based Practice, Research Methodology

\section{Introduction}

Research literature has expanded dramatically over the last several decades. Thousands of health care journals are publishing a myriad of articles annually. With so many investigative reports being published, it would seem logical that all our evidence-practice questions could be readily answered. However, for various reasons, the answers to questions about clinical practice are not all being supported by evidence. One of the causes of a lack of evidence-based decisionmaking is that keeping up with research results is nearly impossible for health care professionals. There are too many research articles for people to read and translate to practice.

Another reason for not having all the answers to clinical practice questions is finding articles that provide evidence of solutions can be difficult. Doing data base searches can be mind-boggling. An even more critical consideration is the wide variations in the robustness of the analysis methods and evidence reporting. Some research projects are rigorous and result in evidence that can be applied to answer complex clinical practice questions. Other research projects may involve the applications of less rigorous methods and article evidence that may lead to more questions than answers. Many times, articles that use rigorous methods and those involving less robust methods appear to be similar.
Thus, identifying scholarly articles that provide strong evidence useful for solving clinical practice issues can be a substantial barrier for health care practitioners [1]. The focus on research review articles can help simplify identifying research findings that can be translated to practice. Research review articles summarize groups of research studies, which can be used to inform evidence-based practice decisions. Reviews of research are becoming more and more critical to improving care and making evidence-based decisions.

One factor that adds complexity to finding, identifying, and using the right research review articles is that multiple types of reviews use different methods [2]. The review approaches and implications for the results are separate for meta-analysis, meta-synthesis, integrative, scoping, and systematic reviews. It is not uncommon for healthcare practitioners to be unfamiliar with the different review methods and the implications for the reviews' findings, adding to the confusion about identifying the most relevant review article to inform their specific practice questions. Understanding the fundamental purposes of the different types of research reviews is critical for nurses and other health care professionals seeking to implement evidence-based practices. In the following pages, we will examine the sixmost popular methods used in scholarly review studies. For each methodology, we will describe the purpose and outcomes, the toolsavailable to determine the reviews' quality, and how each form of review might be used to support practice and research. We will also offer information on developing clinical practice questions and how to locate open-source articles of reviews.

\section{Using Questions to Identify Appropriate Research}

Knowing how to develop clinical questions and locate research articles that can be used to answer themis essential for nurses and other health care professionals seeking to engage in evidencebased practice. If you are not sure of what you are looking for, it is unlikely that you will find it, much less know how to determine the applicability of what you do find. Thus, creating questions that get to the crux of an issue is necessary to guide your search process.

Many practitioners who have care-related questions commonly seek to locate research review articles that compare treatment options. Treatment-focused questions are often asked in a defined format to standardize and simplify the process of finding relevant research articles. Many evidence-based practice models have developed a consistent way of making queries related to treatment options. A common model involves the development and application of a "PICO" question [3]. The acronym, "PICO" represents the various parts of the clinical practice issue. In the PICO format, the "P" representing the patient or populationof focus. The "I" is for 
intervention and describes treatment options of interest. The " $\mathrm{C}$ " stands for comparison and refers to the group receiving different treatment than the primary group in the research. The comparison treatment may be the treatment of the current practice. Finally, the "O" is the out come and represents the treatment result, which may be articulated as positive, negative, or no change.

For example, health care professionals may be considering whether to implement the use of cooling caps to reduce alopecia when people are receiving chemotherapy. Their search for research reviews might focus on whether scalp cooling treatments preserve hair density following therapyat higher rates than people who get the standard therapy with no cooling cap. The PICO questions for determining the outcome for using a cooling capmightbe: $\mathrm{P}=$ people receiving the chemotherapy; $\mathrm{I}=$ the scalp cooling process; $\mathrm{C}=$ no treatment, $\mathrm{O}=$ hair retainment. Thus, the key terms used to search for related research articles would be associated with the different aspects of the PICO questionsframing the research interest in scalp cooling. The focused search increases the likelihood of locating research articles relevant to clinical practice under consideration [3].
However, before searching for articles, it is critical to understand which research reviews are most useful for answering PICO questions.

\section{Reviews of Research}

As we have previously shared, there are multiple different methods for reviewing research. The methods of each type determine how the review might be applied to additional research or to inform evidencebased practice. Thus, understanding the processes and outcomes for reviewing research is fundamental to identifying articles that are likely or not likely to answer PICO questions. The following descriptions and explanations for different research reviews can help guide your searching, identifying, and categorizing review of research articles.

\section{Types of Reviews of Research}

As mentioned previously, there are six main types of scholarly review articles. These include systematic reviews with metanalysis, systematic reviews without metanalysis, integrative reviews, meta-synthesis, non-systematic reviews, and scoping reviews. A thorough explanation of each type of review methodology could fill an entire book. For simplicity's sake, we offer a brief description of each and summarize the information in Table 1.

\begin{tabular}{|c|c|c|c|c|}
\hline Type of Review Reports & $\begin{array}{l}\text { Use to } \\
\text { Answer } \\
\text { PICO }\end{array}$ & $\begin{array}{l}\text { Types and Quantity of } \\
\text { Research Reviewed }\end{array}$ & $\begin{array}{l}\text { S t a t is t i c } \\
\text { Included }\end{array}$ & Main Purpose of the Review \\
\hline 1. SR with Metanalysis & Yes & $\begin{array}{l}\mathrm{Q} \text { u a } \mathrm{n} \mathrm{t} \text { i } \mathrm{t} \text { a } \mathrm{t} \text { i } \mathrm{v} \text { e } \\
\text { research, often, the } \\
\text { studies included are } \\
\text { randomized controlled } \\
\text { trials. }\end{array}$ & $\begin{array}{l}\text { High-level } \\
\text { statistical } \\
\text { analysis }\end{array}$ & $\begin{array}{l}\text { Develop the least biased conclusions } \\
\text { regarding the findings of quantitative } \\
\text { articles chosen through systematic, } \\
\text { reproducible steps.After finding the } \\
\text { articles, a statistical analysis is completed }\end{array}$ \\
\hline $\begin{array}{l}\text { 2. Systematic Review } \\
\text { without metanalysis }\end{array}$ & Yes & $\begin{array}{l}\text { Quantitative research: } \\
\text { including randomized } \\
\text { controlled trials, } \\
\text { retrospective, and } \\
\text { other primary } \\
\text { research. Numbers } \\
\text { vary by topic. }\end{array}$ & 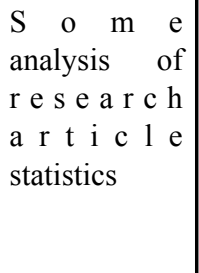 & $\begin{array}{l}\text { Develop unbiased conclusions regarding } \\
\text { findings of literature collected through } \\
\text { a systematic approach to discovering } \\
\text { quantitative articles. }\end{array}$ \\
\hline 3. Integrative Review & Yes & $\begin{array}{l}\text { A mix of quantitative, } \\
\text { qualitative, or mixed } \\
\text { methods* research } \\
\text { articles. Usually, } \\
\text { a small number of } \\
\text { studies included. }\end{array}$ & $\begin{array}{l}\text { May include } \\
\text { some analysis } \\
\text { of article } \\
\text { statistics. }\end{array}$ & $\begin{array}{l}\text { Develop conclusions regarding the } \\
\text { findings of a mix of qualitative and } \\
\text { quantitative articles. }\end{array}$ \\
\hline $\begin{array}{l}\text { 4. "Meta-Synthesis" = } \\
\text { Qualitative Research } \\
\text { Synthesis }\end{array}$ & No & $\begin{array}{l}\text { Review of qualitative } \\
\text { articles on a specified } \\
\text { topic. Usually, few } \\
\text { studies included do } \\
\text { limited numbers of } \\
\text { studies available. }\end{array}$ & $\begin{array}{l}\text { Often very } \\
\text { few if any } \\
\text { statistics } \\
\text { involved. }\end{array}$ & $\begin{array}{l}\text { Develop conclusions regarding findings } \\
\text { of multiple qualitative articles. No } \\
\text { treatment comparisons are made in the } \\
\text { studies, so no PICO answer. }\end{array}$ \\
\hline $\begin{array}{ll}\text { 5. Non-systematic } \\
\text { Reviews }\end{array}$ & Possibly & $\begin{array}{l}\text { Review of articles the } \\
\text { author(s) find relevant } \\
\text { to the chosen topic. } \\
\text { Numbers vary by } \\
\text { topic. }\end{array}$ & $\begin{array}{l}\text { Usually do } \\
\text { not include } \\
\text { statistics }\end{array}$ & $\begin{array}{l}\text { Provide the authors' perspective on } \\
\text { topics. Articles are chosen by the } \\
\text { authors and not systematically. These } \\
\text { can be biased, particularly if written by } \\
\text { individuals with monetary interests in the } \\
\text { subject. }\end{array}$ \\
\hline 6. Scoping Review & No & $\begin{array}{l}\text { Canincludequalitative, } \\
\text { quantitative \& mixed } \\
\text { methods* research. } \\
\text { The topic of interest is } \\
\text { divided into subtopics } \\
\text { and numbers in each } \\
\text { subtopic defined. }\end{array}$ & $\begin{array}{l}\text { Ty p i c a lly } \\
\text { statistics are } \\
\text { used. These } \\
\text { tend not } \\
\text { to include } \\
\text { c o m p l e x } \\
\text { calculations. }\end{array}$ & $\begin{array}{l}\text { Evaluate and define the extent of } \\
\text { published research in a defined area. } \\
\text { No treatment comparisons made, so no } \\
\text { PICO answer. }\end{array}$ \\
\hline
\end{tabular}




\section{Systematic Review with Metanalysis}

Systematic reviews with meta-analysis are excellent sources of research information to answer clinical questions. These reviews include a statistical analysis of previous research [3]. The process of a systematic review involves searching for research articles on the same topic, such as scalp cooling. The search of databases for articles requires a systematic approach using a collection of key terms and noting the number of articles returned from each search. During the search processes, the authors record the steps taken in finding the relevant research articles so others would be able to reproduce their process. The benefit of a systematic search strategy is that it reduces the potential bias that can occur if authors pick and choose articles that best serve their purpose.

The research articles used in developing a systematic review (SR) with meta-analysis are all quantitative, which means they rely on statistics to answer specific study questions. After the keyword searches of relevant databases are completed, the research articles are collected and reviewed. In this step, the author(s) conducting a systematic review examining the articles' contents for the study's focus, including the participants, intervention, comparison, data collected, and analysis results. The informationis reviewed to determine the alignment with an emphasis on the systematic review. For example, a systematic review of scalp cooling research would not include articles on torso cooling, as that is not the focus of the PICO. It is customary for the authors to summarize the research articles used in a review in charts or tables in their research article to legitimize their review process. For a scalp cooling chart, the authors may include information on the length of the treatment, process used, and whether the study results indicate the efficacy of the cooling caps.

The meta-analysis is another step in the review process performed after the systematic search and review of the research articles is complete. A meta-analysis isa statistical process in which the researcher pools the outcomes of each research article, weighs the outcomes based on the sample size, and develops statistics that represents the outcome of all the articles so that results can be compared [4]. The meta-analysis, therefore, considers the strength of the findings in each of the included research study based on the study sample size and the amount of change observed. Using statistical programs, systematic review authors can conduct the metaanalysis to quantify the effectiveness of treatments. These statistical results are oftenplotted in what is termed a "forrest plot" or some other graphical representationto provide readers a visual of the data (i.e., outcome and sample size) included in meta-analysis article publications.

An example of a systematic review of researchwith meta-analysis is [5] work. These three individuals systematically searched for research articles related to the risk of metastases to the scalp following cooling treatment to reduce alopecia in cancer treatment patients. Through a database using keywords, they were able to identify 24 articles. Of those, they found ten relevant research reports. Each of those articles was evaluatedin terms ofsample size and outcomes. Using statistical analysis, Rugo et al. [5] found that scalp metastases' incidence was not large no matter if patients had scalp cooling or not. They concluded that scalp cooling did not significantly increase the risk of metastatic cancer in this patient population.

\section{Systematic Reviews without Meta-analysis}

Systematic reviews of research have become more common and provide excellent sources of information to support evidencebased patient care. The reason for increased popularity is this type of research review provides a synthesis of data from various quantitative research articles. Systematic review researchers engage in the same methodical, reproducible process of searching for the research described in the previous section. The major difference between this type and the last is the authors do not include the statistical comparison between the study findings. In other words, they do not conduct a meta-analysis.

In their systematic review of Ross and Fischer-Cartlidge [6], these nurses searched for research articles in the PubMed and CINAHL databases. The search process focused on tolerance, safety, and the efficacy of scalp cooling treatment on individuals under going cancer treatment. The authors found forty articles in performing their systematic literature search, but only twelve studies met their inclusion criteria and were considered in their research review. In their results summary from the dozen published research reports, the authors found that scalp cooling did reduce hair loss without increasing the risk of metastatic disease to the scalp or decrease survival rates. In the conclusion of the research review article, they suggest that scalp cooling be encouraged. This review as well as others indicate that systematic reviews with out meta-analysis can be useful in answering PICO questions.

\section{Integrative Reviews}

Integrative reviews are a more recently adopted form of reviews, first appearing in 2005 [7]. Authors of integrative studies usea similar systematic literature search using key words and review of the articles as we have previously described. Unlike researchers conducting systematic reviews of the integrative reviews, research authors consider both qualitative and quantitative research articles in the studies reviewed.

Qualitative research methodologies are different from quantitative in several ways. Much of the published healthcare-related qualitative research studies focus on personal experiences, such as emotional reactions to events. Commonly, the number of participants in qualitative research issmaller thanin quantitative research projects. For the most part, qualitative researchers collect data more experientially and develop conclusions by identifying trends in participants' information without using statistical programs.

An example of an integrative review was performed by Abdeljabbar and Al-Atiyyat [8]. They used a systematic approach to search two different databases. The researchers found 54 unique research articles about alopecia treatment in adults under going chemotherapy. Not all met their inclusion criteria - a total of ninearticles that fit their inclusion criteria were reviewed for content. The research articles included results using qualitative and quantitative data. Each of the research studies they included for review provided information on the treatment's effectiveness and how patients reacted to alopecia. Overall, the authors wrote that scalp cooling was cheap and effective. In the article's conclusion, the authors suggested that women were more emotionally affected by hair loss and that research on men who have scalp cooling was lacking. The published article does not make any conclusions about which type of treatment is better than others. As a seen in this example, integrative reviews can include a combination of data and are not strictly quantitative, the reviews can help answer PICO questions and make decisions about evidencebased practice.

\section{Meta-synthesis}

Meta-syntheses are like integrative reviews. However,with metasyntheses, the articles are not always obtained usinga systematic review processor compare two treatment options. Also, theyfocus exclusively on qualitative data for analysis [9]. Frequently, the topics chosen for a meta-synthesis have not been researched extensively, so the amount of research available for review is typically less robust. Hence, the number of research studies included in each metasynthesis tends to be less than integrative and systematic reviews.

Meta-syntheses are not as prevalent in the literature as systematic reviews. Even so, many examples of meta-synthesis can be found in databases such as CINHAL. No specific meta-syntheses could be found on cooling caps, but there were some on women with cancer. For example, Shaw, Sherman and Fitness [10] conducted a metasynthesis that focused on dating concerns with women who had breast cancer or had a genetic susceptibility to this type of cancer. These authors searched five databases for qualitative articles on cancer concerns of women and initially found 1137 related articles. Through screening and determining alignment with the research goal, they narrowed their review to nineteen qualitative studies. Each of the 19 articles was reviewed. The authors were seeking to find common themes within the qualitative study findings. In their published report, Malterud et al. [9] synthesized the data from the 
19 article into six themes related to the women's experiences and feelings. The published findings may be useful for supporting women dealing with susceptibility or actual breast cancer. Comparison of best treatment options was not part of the study results. Thus, this meta-synthesis would not be very help in answering many PICO questions related to enhance evidence-based clinical practices, but these types of studies do provide information that can be used by practitioners.

\section{Non-systematic Reviews}

Some practitioner journals include research review articles that contain information from research articles that are not identified in a systematic process of discovery. Thus, the methods used for nonsystematic reviews are not reproducible. Having authors choose research articles without documenting the methods used can lead to bias choices. Bias is also more likely if the authors of non-systematic reviews have economic interests in the topic they are investigating and reporting. The potential for personal benefit as motivation for a non-systematic review could lead to sharing opinions supported in research studies and contradicted in other research articles. When reading a non-systematic review, we recommend health care practitioners watch for information related to authors' employment, funding sources, or different situations that may lead to bias in reporting. However, the higher chance of bias does not mean that these articles do not have value and should not be read. The potential for bias does mean that consideration of a non-systematic review's outcomes should be considered cautiously and with some skepticism.

\section{Scoping Reviews}

Scoping reviewsare sometimes called "mapping reviews," and are a relatively newer method for reviewing research. The process of producing scoping reviews is less standardize than a systematic review, but new guidelines on performing a scoping review should help guide future work [11]. The general goal of scoping reviews of research is to determine how published articles of research of a topic exist. To conduct a scoping review, most authors develop a list of keywords representative of the issue of interest. They then perform a systematic search of multiple databases to find potential research articles for review. The papers found using are collected and then reviewed for topic alignment, relevance, and methodology. Researchers will then check only the articles that were deemed acceptable for consideration.

In reviewing the literature, the scoping review authors may include policy documents in addition to research [11]. After reading through the relevant documents, the review researchers will describe what was found in the articles and often define what gaps there are in the literature. As a result, the reviews usually do not provide answers to specific patient care related research questions, but help researchers decide on future research topics and trends in current research.

Even though scoping reviews may not directly influence practitioners' care, the findings can help provide a better understanding of what research is available and provide direction for future research in particular areas. For example, a scoping review of literature related to cancer treatment was conducted by an investigative team. Wagland et al. [12] review article includes information about 98 located research reports. In terms of these findings, the review results indicate there are many issues related to chemotherapy treatment. Commonly reported problems included nausea, vomiting, and fatigue. They hope to use their findings to help monitor patient issues in the future in order to see if there are changes that should be addressed. In this scoping review, treatments are not addressed.

This article provides some thought-provoking results for practitioners. However, like other scoping reviews, this does not provide outcomes that could be useful for answering PICO questions but may give some insight into related research.

\section{Evaluation of the Quality of Review of Research Articles}

As with any article, evaluating the work's quality is needed before applying the findings to practice. To help guide the assessment process, having rubrics or scoring form is helpful. There are many other evaluation tools available for evaluating a variety of review types. Three prominent organizations' assessment checklists are presented in this section. These specific evaluation forms are very credible, functional, and are cost-free.

\section{Cincinnati Children's Hospital LEGEND Tools}

The first was developed by the James M. Anderson Center for Health Systems Excellence at the Cincinnati Children's Hospital [13]. The "Let Evidence Guide Every New Decision" (LEGEND) tools created by this organization are available online and provide excellent forms to appraise many different types of research articles and reviews (2020).There is one specifically designed to review "systematic reviews/meta-analysis." Questions included on the tool include "Were the methods consistent from study to study?" and "Was there freedom from conflict of interest?" [14]. This and other documents can be downloaded from their website along with the grading of the evidence tool. See Table 2 for more information on these assessments.

\begin{tabular}{|l|l|l|l|l|}
\hline Type of Review Reports & $\begin{array}{l}\text { Use to } \\
\text { Answer } \\
\text { PICO }\end{array}$ & $\begin{array}{l}\text { Tools Available } \\
\text { for Reviews }\end{array}$ & LEGEND Rating & Strength of This Type of Review \\
\hline $\begin{array}{l}\text { SR with Meta- } \\
\text { analysis }\end{array}$ & Yes & $\begin{array}{l}\text { CASP } \\
\text { JBI* } \\
\text { LEGEND }\end{array}$ & $1 \mathrm{a} \& 1 \mathrm{~b}$ & $\begin{array}{l}\text { Considered to be the strongest type of } \\
\text { review. }\end{array}$ \\
\hline 2. $\begin{array}{l}\text { Systematic Review } \\
\text { Yes }\end{array}$ & $\begin{array}{l}\text { CASP } \\
\text { JBI* } \\
\text { LEGEND }\end{array}$ & 1 a \& 1b & $\begin{array}{l}\text { Can be strong depending on the } \\
\text { number of studies found and processes } \\
\text { used to review. }\end{array}$ \\
\hline $\begin{array}{l}\text { Integrative Review } \\
\text { Synthesis }\end{array}$ & Yes & JBI* & Not Rated & $\begin{array}{l}\text { Strength is limited, usually due to a } \\
\text { limited number of research articles } \\
\text { available on the topic to review. }\end{array}$ \\
\hline
\end{tabular}

table 2 . to be a cont.... 


\begin{tabular}{|l|l|l|l|l|}
\hline $\begin{array}{l}\text { 5. } \begin{array}{l}\text { Non-systematic } \\
\text { Reviews }\end{array} \\
\text { Possibly }\end{array}$ & LEGEND*** & $5 \mathrm{a}$ or $5 \mathrm{~b}$ & $\begin{array}{l}\text { These articles are often written in an easy to } \\
\text { read manner and include the results of multiple } \\
\text { research articles. }\end{array}$ \\
\hline 6. Scoping Review & No & $\mathrm{JBI}^{*}$ & Not Rated & $\begin{array}{l}\text { The strength of this type of research is to help } \\
\text { direct future scholarship as it can show areas } \\
\text { where more research is needed. However, no } \\
\text { comparisons between treatments are made in } \\
\text { these types of scholarly projects. }\end{array}$ \\
\hline $\begin{array}{l}\text { *The JBI = Joanna Briggs Institute tool is a general tool designed to evaluate all review articles and not specific to } \\
\text { any particular type of review process. } \\
\text { The LEGEND tool for Meta-Synthesis is a general tool for reviewing qualitative research and is not specific to } \\
\text { meta-synthesis analysis } \\
* * * * \\
\text { The LEGEND offers a tool for evaluation of "Expert Opinion" reports. }\end{array}$
\end{tabular}

Table 2. Use and strength in practice application and evaluation tools.

\section{CASP UK Tools}

Another organization that provides free tools for evaluating research is CASP UK. This association also has various assessment check lists that can help practitioners review primary research and review articles to determine their quality. These are readily available on their website, along with instructions on how to complete each one. Even though the number of assessment tools is not as large, these forms have been used for many years and are highly regarded by researchers and practitioners.

\section{Joanna Briggs Institute Appraisal Tools}

A third organization worth mentioning is the Joanna Briggs Institute (JBI) [15], based in Australia. JBI [15] offers free critical appraisal tools that are used internationally. One specific assessment form does provide a framework for the evaluation of review articles. Although not specific to one of the review methodologies, the assessment tool can help practitioners identify research articles' strengths and weaknesses. Questions included on the tool include: "Was the search strategy appropriate?" and "Was the likelihood of the publication bias assessed?"

Health care practitioners can use the tools developed by CASP UK, the Anderson Center, and JBI on their own, but doing a group evaluation of review articles and comparing results can help spur conversation about the topic and lead to a better understanding of the findings. Before changes in practice are made, a group consensus on the change is critical to assure a successful transformation of care practices.

\section{Cincinnati Children's Hospital Scoring Types of Research Methodology}

Scoring articles by type can also help practitioners determine the strength of research studies. One can use a rating scale to help identify the article's credibility. When reading research review articles, those that score higher can help in decision making regarding practice changes. Some organizations have developed scoring rubrics for various research reviews [4].

In addition to providing a checklist to evaluate specific research articles, the Cincinnati Children's Hospital James M. Anderson Center [14] has developed a scoring scheme for various evidence levels (2020). The highest score is a "la," and the lowest is a " 5 b." The 1a is given to well-performed systematic reviews with metanalysis. The low scores are assigned to articles based on little or no empirical evidence, including expert opinions and care guidelines.

\section{Locating Free Research Review Articles}

Knowing how to evaluate a research review article is essential but getting a copy of the manuscript is also critical to understanding best practices and making clinical practice changes. Many research reviews are available online. Some have a fee associated with them, and others are provided free of charge. Some sites can help practitioners find the articles they are looking to read. A few that we recommend include Scholar Google, ResearchGate, and Trip.

All three of these sites provide access to millions of free research articles for practitioners to use to improve patient care. Each has strengths and weaknesses. Overall, we do recommend you explore each as well as other available sites. See Table 3 for additional information on these resources.

\begin{tabular}{|l|l|l|l|}
\hline Name of Service & Overview & Link & Other Comments \\
\hline $\begin{array}{l}\text { Scholar Google } \\
\text { (SG) }\end{array}$ & $\begin{array}{l}\text { Millions of articles to } \\
\text { search. A link on the right } \\
\text { of the findings links to free } \\
\text { articles. }\end{array}$ & $\begin{array}{l}\mathrm{https} / / \mathrm{sch} \text { colar.google. } \\
\mathrm{com} /\end{array}$ & $\begin{array}{l}\text { Can be overwhelming. Does allow } \\
\text { you to save SG articles and inform } \\
\text { you if articles are published in an } \\
\text { interesting area. }\end{array}$ \\
\hline ResearchGate & $\begin{array}{l}\text { This is much like Facebook } \\
\text { for researchers. Many } \\
\text { researchers upload their } \\
\text { articles to the site. }\end{array}$ & $\begin{array}{l}\mathrm{https} / / \text { www.researchgate. } \\
\text { net/ }\end{array}$ & $\begin{array}{l}\text { Must make an account, but it is } \\
\text { free. Some researchers are more } \\
\text { likely to respond than others. } \\
\text { Can post questions about research } \\
\text { and network with other }\end{array}$ \\
\hline Trip & $\begin{array}{l}\text { Millions of articles. Most } \\
\text { are free. Able to input a } \\
\text { PICO question and the } \\
\text { system will search for } \\
\text { answers. }\end{array}$ & $\begin{array}{l}\text { Must make an account. There is a } \\
\text { com//www.tripdatabase } \\
\text { free version and paid. } \\
\text { Does access many articles that are } \\
\text { from outside of the US. }\end{array}$ \\
\hline
\end{tabular}


If you want to find other sites and are unsure where to start searching for additional online resources, we recommend viewing sites that rate health-related article database ratings. There are many free to access. For example, there is a best online medical research journals blog located at https://blog.capterra.com/top-sites-for-reading-medicaljournals-online-for-free/

The National Library of Medicine manages another helpful site. The webpage includes an extensive list of databases and directors. Not all of the listed resources are free, but the NLM clearly designates "onsite Access Only' = not free to the public. Find out more by using this link: https://www.nlm.nih.gov/services/databases_abc.html

\section{Conclusions}

Finding research studies that answer the many questions practitioners have regarding best practices is key to evidence-based practice. Using quality research review articles is a way to help find answers. There are many types of research reviews. Not all have the primary purpose of answering clinical care questions. So, selecting the most useful research reviews can save time and, in some cases, money.

The majority of review articles can help to find best practices. Frequently, systematic reviews with metanalysis are excellent sources of information for practitioners. The authors of these articles summarize research study results and provide suggestions for practicechanges if appropriate.

Before evidence and change are implemented into patient care settings, practitioners need to assess the quality of research reviews and deciding on whether to make a practice change or not. Many tools can help nurses and other health care professionals find research, such as Google Scholar and Research Gate, and determine the quality of the literature, including the LEGEND and CASP tools. We hope you will use these and the many others available online.

Conflict of interests: The authors declare no conflict of interest.

\section{References}

1. Mathieson, A., Grande, G., \& Luker, K. (2019). Strategies, facilitators and barriers to implementation of evidence-based practice in community nursing: a systematic mixed-studies review and qualitative synthesis. Primary Health Care Research \& Development, 20.

2. Snyder, H. (2019). Literature review as a research methodology: An overview and guidelines. Journal of Business Research, 104, 333-339.

3. Polit, D. F., \& Beck, C. T. (2018). Essentials of Nursing Research: Appraising Evidence for Nursing Practice (9th ed). Lippincott Williams \& Wilkins.

4. Melnyk, M. \& Fineout-Overholt, E. (2019). Evidence-Based Practice in Nursing and Healthcare: A Guide to Practice. Wolters-Kluwer.

5. Rugo, H. S., Melin, S. A., \& Voigt, J. (2017). Scalp cooling with adjuvant/neoadjuvant chemotherapy for breast cancer and the risk of scalp metastases: systematic review and meta-analysis. Breast Cancer Research and Treatment, 163(2), 199-205.

6. Ross, M., \& Fischer-Cartlidge, E. (2017). Scalp Cooling. Clinical Journal of Oncology Nursing, 21(2).

7. Hopia, H., Latvala, E., \&Liimatainen, L. (2016). Reviewing the methodology of an integrative review. Scandinavian Journal of Caring Sciences, 30(4), 662-669.

8. Abdeljabbar, H. M., \& Al-Atiyyat, N. (2013). Cooling Scalp with Chemotherapy Include Alopecia among Cancer Patients: Integrative Review. Middle East Journal of Nursing, 101(899), $1-4$.

9. Malterud, K. (2019). The impact of evidence-based medicine on qualitative metasynthesis: benefits to be harvested and warnings to be given. Qualitative health research, 29(1), 7-17.
10. Shaw, L. K., Sherman, K., \& Fitness, J. (2015). Dating concerns among women with breast cancer or with genetic breast cancer susceptibility: A review and meta-synthesis. Health Psychology Review, 9(4), 491-505.

11. Peters, M. D., Marnie, C., Tricco, A. C., Pollock, D., Munn, Z., Alexander, L., ... \& Khalil, H. (2020). Updated methodological guidance for the conduct of scoping reviews. JBI Evidence Synthesis, 18(10), 2119-2126.

12. Wagland, R., Richardson, A., Armes, J., Hankins, M., Lennan, E., \& Griffiths, P. (2015). Treatment-related problems experienced by cancer patients undergoing chemotherapy: a scoping review. European Journal of Cancer Care, 24(5), 605-617.

13. Cincinnati Children's Hospital Medica Center (2012). LEGEND: Evidence Appraisal of a Single Study Intervention Systematic Review/Meta-Analysis. https://www.cincinnatichildrens.org/ research/divisions/j/anderson-center/evidence-based-care/ legend

14. Cincinnati Children's Hospital Medical Center (2020). Evidence Evaluation Tools \& Resources. https://www.cincinnatichildrens. org/research/divisions/j/anderson-center/evidence-based-care/ legend

15. The Joanna Briggs Institute (2020), Checklist for Systematic Reviews and Research Syntheses. https://joannabriggs.org/sites/ default/files/2020-08/Checklist_for_Systematic_Reviews_and Research_Syntheses.pdf 